\title{
Capturing and Radio Ear-Tagging Neonatal Vicuñas
}

\author{
EMILIANO DONADIO, ${ }^{\mathbf{1}}$ Program in Ecology $\&$ Department of Zoology and Physiology, University of Wyoming, Laramie, WY 82071, USA \\ MARIEL RUIZ BLANCO, Facultad de Ciencias Naturales, Universidad Nacional de La Plata, La Plata 1900, Buenos Aires, Argentina \\ RAMIRO D. CREGO, Cooperative Wildlife Research Laboratory, Southern Illinois University, Carbondale, IL 62901, USA \\ STEVEN W. BUSKIRK, Program in Ecology E Department of Zoology and Physiology, University of Wyoming, Laramie, WY 82071, USA \\ ANDRÉS J. NOVARO, INIBIOMA, CONICET E Patagonian and Andean Steppe Program, Wildlife Conservation Society, \\ Junin de los Andes 8371, Neuquén, Argentina
}

\begin{abstract}
We used and evaluated the effectiveness of a hand-capture technique to capture and mark neonatal vicuñas (Vicugna vicugna) at San Guillermo National Park, west-central Argentina. We captured and marked 98 neonates during 5-31 January, 2008-2010. Capture success was 92\% (106 attempts), with stationary marking teams being 2.5 times as successful in detecting and capturing neonates as mobile ones. Of neonates captured, $99 \%$ were $<1$ day old. Of these, average age at capture was 11.9 minutes $(95 \%$ $\mathrm{CI}=11-13 \mathrm{~min}$ ); neonates $>20$ minutes old typically were too mobile to capture. Sex ratio at capture was biased toward males (1.5:1), while mean body weight and neck circumference were similar between sexes. Generally, mothers remained in sight during, and immediately reunited with their neonates after, capture. Four percent of the mothers ran out of sight but then returned, while $2 \%$ failed to return. Capture-related mortality was $5 \%$, with maternal abandonment in response to capture activities $(n=3)$ the leading cause. Ear-tag transmitter had minimal effects on subsequent ear position. The success of our technique likely was based on terrain (flat) and vegetative conditions (short grass), high densities of animals for monitoring (particularly in a meadow), and a predictable, pulsed birth season. This hand-capturing method was efficient for handling and marking neonatal vicuñas. Combined with the use of ear-tag transmitters, it allows the study of important perinatal processes, including movement and mortality. (c) 2012 The Wildlife Society.
\end{abstract}

KEY WORDS capture techniques, neonates, South America, ungulates, Vicugna vicugna, vicuña.

Population growth in ungulates can be highly sensitive to juvenile survival (Gaillard et al. 2000), and behaviors and movements of juveniles are informative about other population processes such as habitat selection, dispersal, and migration. Survival of juveniles has been shown to vary widely from year to year in response to environmental conditions or predator abundance (Gaillard et al. 1998, 2000). Therefore, knowing the fates of juvenile ungulates is important to conserving and managing their populations.

The vicuña (Vicugna vicugna) is 1 of 2 wild camelid species endemic to South America. Once near extinction, vicuñas have recovered steadily over the last 4 decades (Torres 1992, Baigún et al. 2008, Wheeler and Laker 2009). This recovery has resulted in new conflicts in some areas, as herders begin to perceive them as potential competitors with livestock for food and water (Lichtenstein and Vilá 2003). Consequently, the vicuña has become the focus of sustainable use programs, including management of wild and captive populations. The latter, however, has been criticized on ecological, conservation and socioeconomic grounds, with management of wild populations suggested as a superior alternative (Vilá 2002,

Received: 28 July 2011; Accepted: 31 December 2011;

Published: 22 February 2012

${ }^{1}$ E-mail: emiliano@uwyo.edu
Lichtenstein 2006, Vilá and Lichtenstein 2006). Managing wild populations requires knowledge of the species' demography, and no data on vicuña vital rates are available. Particularly for the crucial juvenile stage, the lack of reliable capture methods has been a constraint in estimating vicuña survival (Sarno 2010).

Herein, we describe an efficient means of capturing and studying the fates of juvenile vicuñas. Specifically, we present the first data on the application of a hand-capture method to neonate vicuñas, compare our results with those of Franklin and Johnson (1994) for the closely related guanaco (Lama guanicoe), emphasize the modifications needed to successfully apply this technique to vicuñas, and describe cases of capture-related mortality.

\section{STUDY AREA}

We captured vicuñas in northern San Guillermo National Park (SGNP; $29.06811^{\circ} \mathrm{S}, 69.34916^{\circ} \mathrm{W}$ ), the core of the larger San Guillermo Biosphere Reserve, located in the high Andes of west-central Argentina. The 180,000-ha park protected pristine habitats and a complete assemblage of native vertebrate species, including both of the South American camelids, the vicuña and guanaco. Located at approximately $3,600-\mathrm{m}$ elevation, the climate in the area was cold and dry, with a mean annual temperature of $6.7^{\circ} \mathrm{C}$ (min. 
annual average $=-4^{\circ} \mathrm{C}$, max. annual average $=14^{\circ} \mathrm{C}$ ). Precipitation ranged from $20 \mathrm{~mm} /$ year to $300 \mathrm{~mm} /$ year and occurred primarily during the warm season (Dec-Feb; Salvioli 2007).

The study area was characterized by a plain with scarce plant cover $(\bar{x}$ cover $[95 \% \mathrm{CI}]=13 \%[11-15 \%])$, which was also low in height $(5.3 \mathrm{~cm}[4.3-6.2 \mathrm{~cm}])$. Dominant plants were grasses, mainly Stipa spp and Jarava spp. A 118-ha meadow around which our efforts were concentrated featured greater plant cover (75\% [66-83\%]) and taller $(18.8 \mathrm{~cm}$ [16.2-21.3 cm]) grasses, mainly Juncus spp. and Festuca spp. Pumas (Puma concolor) were the only effective vicuna predator present in the area; culpeo foxes (Lycalopex culpaeus), also present, may occasionally prey on vicuña neonates (Hofmann et al. 1983).

Vicuña densities ranged from 0.2 individual/ha on the open plain (Puig and Videla 2007) to 4.9 individual/ha in meadows (Perrig et al. 2010). The high concentration of vicunas in the meadow and adjacent open plain allowed us to visually scan an average of 217 individuals/day (range $=22$ $425)$ during the parturition season. Habituation by vicuñas to our presence allowed us to observe them from $\geq 50 \mathrm{~m}$ without eliciting a disturbance response. The short grasses, flat terrain, and abundant vicuñas facilitated our search for females near and during parturition.

\section{METHODS}

We captured and marked neonate vicuñas between 5 and 31 January, 2008-2010. Marking kits included Global Positioning System receivers (Garmin 60; Garmin, Olathe, KS), spring scales (Pesola ${ }^{\circledR}$ Macro-Line, $20 \mathrm{~kg}$; Pesola, Baar, Switzerland), stopwatches, cloth tapes, pliers, and ear-tag transmitters (Model 3430, $18 \mathrm{~g}$; Advanced Telemetry Systems, Isanti, MN) with mortality sensors. We recorded habitat type, beginning and ending birth time, handling and reunion time, mother and group behavior during capture, and several attributes of captured neonates: sex, neck circumference, weight, and behavior. To capture neonates, we adapted the 4-stage hand-capture method for open-habitat ungulates described by Franklin and Johnson (1994), which included detection, approach and capture, processing and tagging, and reuniting neonate and mother.

\section{Detection}

We visually searched for females near parturition, or for recently (i.e., $<20 \mathrm{~min}$ ) born calves. Teams watched animals from $50 \mathrm{~m}$ to $800 \mathrm{~m}$ away during $0830-1700$ hours. Depending on personnel, 1-3 teams searched from 3 stationary points around the meadow, while $1-2$ teams drove back and forth on a 20-km-long dirt road that dissected the open plain. Most commonly, tagging teams comprised 2 people; number of workers varied daily from 3 to 10 (typically 5). We avoided on-foot searching because vicuñas showed a disturbance response to humans outside vehicles; they ignored those sitting stationary or in vehicles. Binoculars, spotting scopes and portable very high frequency radios were used to detect births and coordinate efforts.
Before parturition, near-term mothers presented distended abdomens, looked repeatedly to their flanks, alternately and frequently stood and lay down, held their tails in either a horizontal or vertical position, and in some cases moved away from nearby conspecifics. A swollen vulva with neonatal feet protruding was an unmistakable sign of imminent birth.

\section{Approach and Capture}

After birth, we allowed the neonate-mother pair to interact for $\geq 10$ minutes unless the neonate attempted to stand sooner. Then 2 team members approached the pair, walking together at a moderate pace (approx. $1 \mathrm{~m} / \mathrm{sec}$ ), avoiding running or any other rapid movement as much as possible. We walked directly to the neonate, pausing if the mother moved more than approximately $50 \mathrm{~m}$ away from the neonate and continuing forward when she returned within approximately $50 \mathrm{~m}$. In such a way we expected to keep the female in sight. Some mothers would not leave their calves; we waved arms and yelled at the mother to induce her to retreat. Our goal was to gain access to the neonates, but to keep mothers within sight and at a safe distance.

Generally, neonates were caught before they could walk; if able to walk, however, they were grabbed by the body, never by the neck or legs. One team member kneeled over the neonate to restrain and process it. Meanwhile, the second team member stood 10-15 $\mathrm{m}$ away, monitoring the behavior of the mother. This person maintained visual contact with the mother and kept her away from the worker who was processing the neonate. If the mother approached aggressively, the watcher alerted the other team member, who would release the neonate and retreat if necessary to avoid physical contact with the mother. In these cases, capture efforts were abandoned (i.e., second captures attempts were never conducted).

\section{Processing and Tagging}

Neonates were affixed with ear-tag transmitters, then sexed, weighed and measured. We placed ear-tag transmitters in the middle of the pinna near its base (Fig. 1). We recorded weight to the nearest $0.2 \mathrm{~kg}$ using an adjustable harness around the chest and forelimbs; the harness was hung from a spring scale (Fig. 2). We measured neck circumference with a cloth tape to the nearest $1 \mathrm{~mm}$ at the middle of the neck. All the processing was conducted by 1 person. In some cases we released neonates before all measurements were completed, due to maternal aggressiveness.

\section{Reuniting Neonate and Mother}

If neonates remained lying when released and the mother was in sight, we quickly moved away from the mother. When neonates were mobile and followed us, we lay down on the ground until the neonate spotted its mother. In these cases, mothers typically walked or ran around us, vocalizing to the neonate until it saw and approached her. In a few cases, we successfully led neonates back to their mothers (Franklin and Johnson 1994). If the mother was not visible, we moved quickly away from the capture site to allow the mother to return and reunite. In a few cases, we carried the neonate 

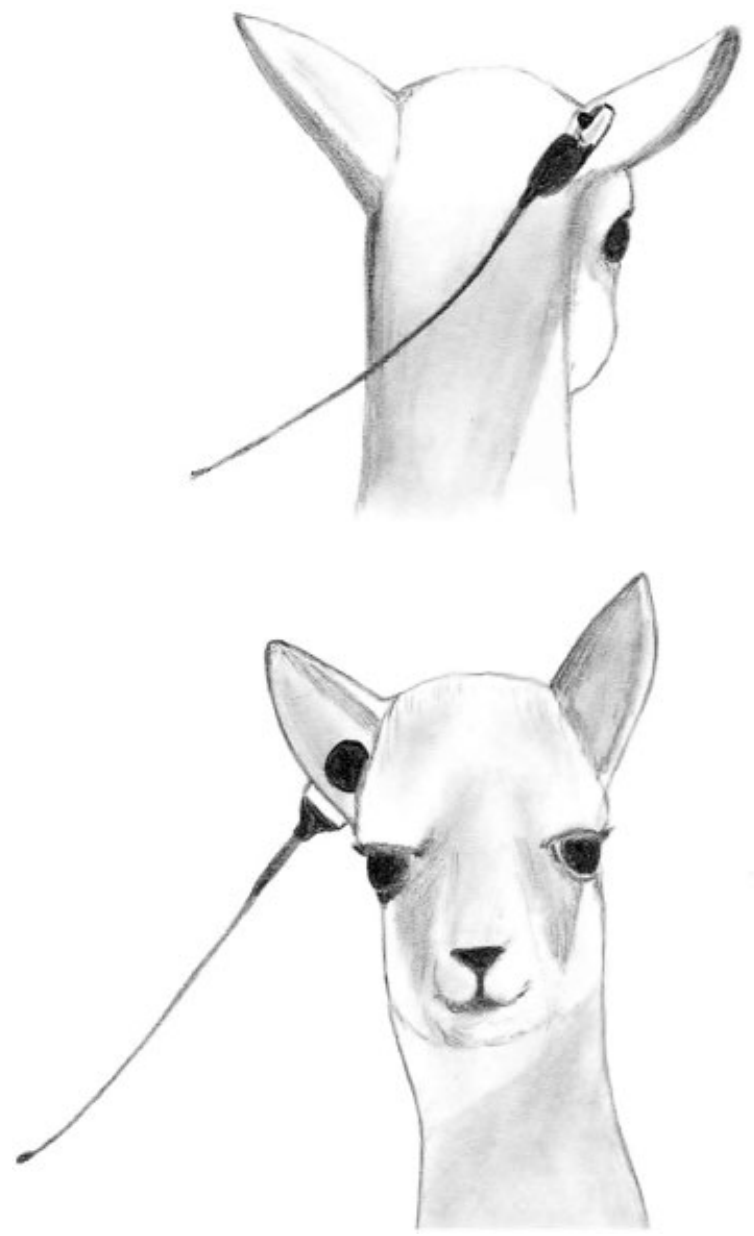

Figure 1. Ear-tag transmitters were placed in the middle of the pinna near its base. Transmitters that were attached too close to the edge or tip of the pinna resulted in transmitters falling off, or permanently depressed pinnas, respectively.

close to where the mother was last observed. Reuniting was considered successful when 1) the female led the neonate away, or 2) the female ran from sight during capture, but the neonate was observed the next day accompanied by, or nursing from, an adult.

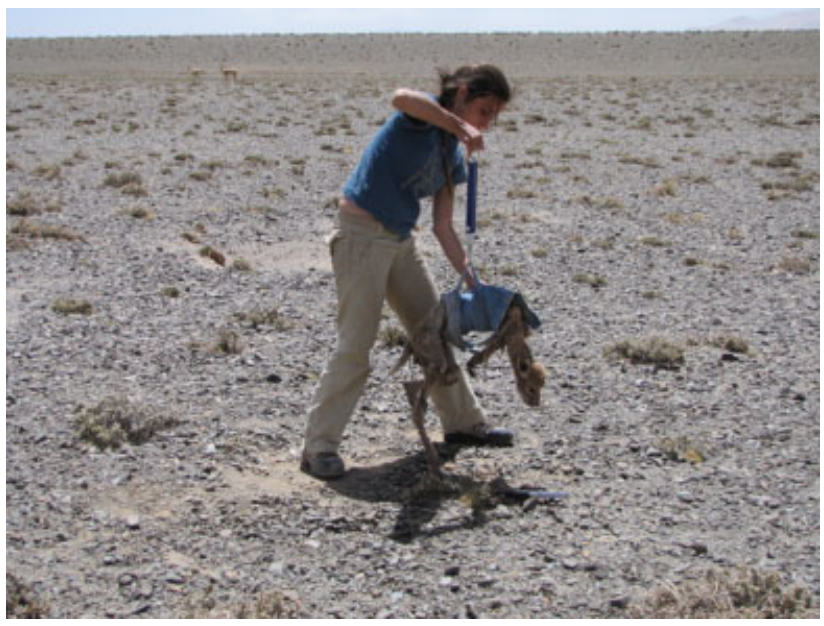

Figure 2. Weighing a 10-minute-old hand-captured vicuña at San Guillermo National Park, Argentina, January 2010.

\section{RESULTS}

We hand-captured and affixed with ear-tag transmitters 98 neonatal vicuñas $(2008, n=7 ; 2009, n=48 ; 2010$, $n=43$ ). Stationary and mobile teams accounted for $72 \%$ and $28 \%$, respectively, of the total captures. Sex ratio at capture was biased toward males 1.5:1 $\left(\chi^{2}=4.1, \mathrm{df}=1\right.$, $P=0.04)$. Mean body weight at birth was similar between females $\quad(5.7 \mathrm{~kg} ; \quad 95 \% \mathrm{CI}=5.5-6.0 ; \quad$ range $=4.0-7.0$; $n=34)$ and males $(5.7 \mathrm{~kg} ; 95 \% \mathrm{CI}=5.5-6.0$; range $=$ $3.8-7.4 ; n=56)$. Likewise, mean neck circumference did not differ significantly between females $(147 \mathrm{~mm}$; 95\% $\mathrm{CI}=141-154 ; \quad$ range $=120-200 ; n=26)$ and males $(152 \mathrm{~mm} ; 95 \% \mathrm{CI}=149-156$; range $=120-190 ; n=54)$. Neonates stood soon after birth $(\bar{x}=23$ min; mode $=16$; $95 \% \mathrm{CI}=17-31 ;$ range $=4-137 ; n=40)$ and followed females 1-5 minutes later.

Overall capture success was 92\% (106 attempts), with 75\% of captures occurring during 1000-1400 hours. Of neonates captured, 99\% were $<1$ day old; the remaining animal, captured while sleeping, was 2-3 days old. Average age at capture for neonates $<1$ day old was 11.9 minutes $(95 \%$ $\mathrm{CI}=11-13$; range $=3-29 ; n=71)$. Average handling time was 90 seconds $(95 \% \mathrm{CI}=60-120$; range $=21-600$; $n=94)$. Unsuccessful capture attempts included 5 neonates $(\bar{x}$ age $=32 \mathrm{~min} ;$ range $=20-60)$ that outran us and 3 females that did not retreat, hampering our capture efforts.

Of the 97 captured animals that were $<1$ day old, we observed the births of 74 , whereas 23 were found 520 minutes after birth, as suggested by their wetness and poor physical coordination. Of females giving birth or accompanied by recently born calves, $40 \%$ were alone; the remainder were with, or near, their family groups $(n=75)$. Group behavior $(n=45)$ during the capture process included retreating but remaining, either watching or running in circles, within $40 \mathrm{~m}$ of the tagging team (24\%), retreating and remaining either watching or feeding 40-600 m away (58\%), and running out of sight (18\%).

During the 98 captures, mothers either stood watching or running around the tagging team at $<21 \mathrm{~m}(26 \%), 21-40 \mathrm{~m}$ (16\%), and $40-800 \mathrm{~m}(52 \%)$. Four percent of the mothers ran out of sight but then returned, while $2 \%$ apparently failed to return. Of the 25 mothers that stayed $<21 \mathrm{~m}$ from the tagging team, 7 launched attacks that included spitting, attempts at kicking with their forelimbs and chest ramming; only 2 of them made contact with workers.

For all captures $(n=98)$ reunion success was $97 \%$ with an average time to reunion of 2.7 minutes $(95 \% \mathrm{CI}=2-4$; range $=0.16-28 ; n=88)$. Ninety-one mother-neonate pairs reunited without help (including 4 mothers that ran out of sight but returned several hours later), 1 neonate was led to its mother by workers, and 1 neonate was carried $50 \mathrm{~m}$ from an area of tall to short grass to make it visible to the mother. Five neonates $(2 \mathrm{~F}, 3 \mathrm{M})$, described below, died due to capture-related factors. Immediately after reunion, 14 mothers either kicked their neonates or the ground nearby in an attempt to force neonates to the ground, while 4 mothers reacted with fear to smelling the ear-tag and retreated one or several times before final reunion. 
On 7 occasions neonates followed workers, who would then lay immobile on the ground (sometimes only a few meters away from the neonate), becoming undetectable. Neonates then switched their attention to the mobile mother. On 4 occasions after the neonate was processed, mothers became confused and followed a truck $(n=2)$ or walking workers $(n=2)$ that were moving away from the capture site. In one case, the female stopped following the truck and returned to its neonate. In a second case, we drove the truck, leading the mother, back to the capture site, where the pair reunited. In a third case, the mother stopped following us when we entered the truck and drove away. In a fourth case, we walked back to the capture site and carried the neonate to an open area where the mother could see it.

Of our captures, $5 \%$ resulted in neonatal deaths. Three neonates were abandoned by their mothers during tagging, the 2-3-day-old animal was apparently abandoned 2 hours after successful reunion, and 1 neonate died after successful reunion, when its mother accidentally kicked it in the head displaying protective behavior. All 4 abandoned neonates died in 3-5 days due to starvation, predation, or unknown causes.

Of the 98 ear-tag transmitters attached, 2 fell off because they had been attached too close to the edge of the pinna, and $\geq 5$ lost their antennas (but continued functioning) several months after being attached. Bleeding from the pinna while transmitters were being attached was noted in only 3 individuals. Transmitter weight kept the pinna depressed during the first 7-10 days; afterward, most pinnas adopted the normal upright position (Fig. 3). Five neonates showed permanently depressed pinnas because transmitters were attached too close to the tip.

\section{DISCUSSION}

The hand-capturing method described here was an efficient mean of handling and marking neonatal vicuñas. Successful application of this technique was likely based on terrain and vegetative conditions (flat with short grass), high densities of animals for monitoring (particularly in the meadow), and

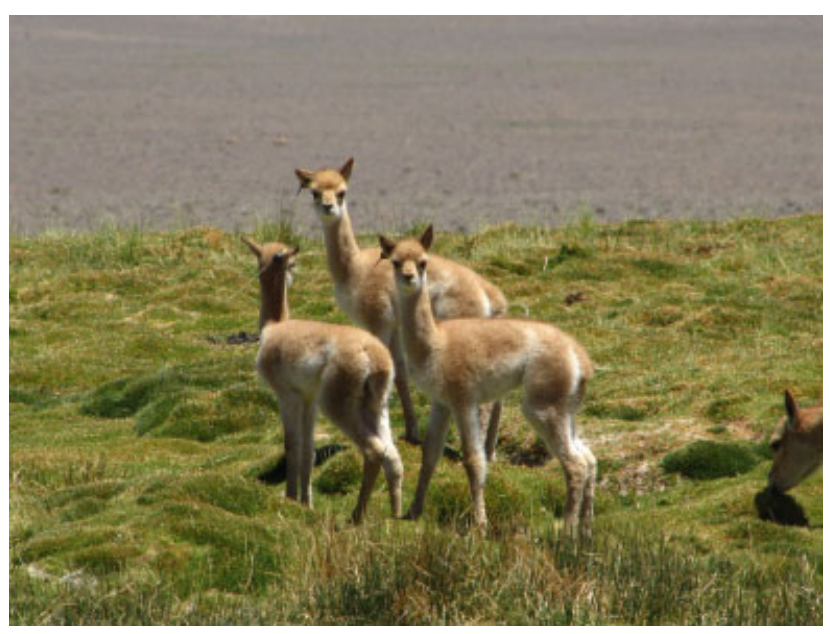

Figure 3. Three 3-week-old vicuñas with attached ear-tag transmitters, in San Guillermo National Park, Argentina, January 2010. a predictable, pulsed birth season. Key elements of the approach included prompt location of neonates after parturition, allowing time for mother-neonate bonding before capture, brief handling times, and prompt and, in some cases, facilitated reunions. Published information (Franklin and Johnson 1994) on the technique in a closely related species facilitated our adoption of the method.

Unlike guanacos at Torres del Paine (Franklin and Johnson 1994), vicuñas in our area became alarmed when teams moved on foot. Another difference was that, during the day, $\leq 425$ vicuñas concentrated in the meadow. Consequently, we could monitor many vicuñas from stationary points, making mobile teams (which worked best for guanacos that had a less aggregated distribution; Franklin and Johnson 1994) less useful. Furthermore, 4-7 workers divided into 2-3 teams were sufficient to monitor the concentrated vicunas, dramatically reducing the number of people needed relative to efforts required for other ungulates (White et al. 1972, Franklin and Johnson 1994, Carstensen Powell et al. 2005). Our results suggest that stationary teams should be favored under aggregated ungulate distributions, whereas mobile teams, either on-foot or in vehicle, should be favored under random or uniform distributions.

Maternal vicuña behavior before, during, and after parturition, and maternal and group behavior during and after captures, were similar to that reported for guanacos (Franklin and Johnson 1994). However, vicuña neonatal behavior differed somewhat, and adaptation of the technique developed for guanacos was necessary. First, neonate vicuñas stood up sooner and developed speed and agility more quickly than guanacos. Consequently, for neonates $<1$ day old, guanacos were caught when older $(\bar{x}=107 \mathrm{~min})$ than vicunas. For guanacos, workers waited until $\geq 15-20$ minutes after birth before approaching neonates (Franklin and Johnson 1994); our attempts to capture vicuñas 20-60 minutes old were unsuccessful because they were too mobile. Timing our capture attempts was critical. If the capture was attempted too early, neonate-mother imprinting could be disrupted, resulting in abandonment. If we attempted capture too late, mobile neonates could outrun workers, or follow them upon release. Capturing vicuña neonates as soon as they attempt to stand or 10-15 minutes after birth (whichever occurs first) was an effective strategy that balanced animal welfare and capture success.

Capture-related mortality was lower than markinginduced mortality of newborn North American ungulates $(\bar{x}=8 \%$, median $=6 \% ;$ range $=0.5-28 \% ; 44$ studies reviewed by Livezey 1990) but higher than that reported for guanacos (approx. 1\%; Franklin and Johnson 1994). During our study, maternal abandonment in response to capture activities $(n=3)$ was the leading cause of neonate mortality. These events included the following: workers capturing a neonate too soon after birth, impeding full bonding with its mother; a lengthy search (5-10 $\mathrm{min}$ ) for a neonate hidden in tall grass with workers losing visual contact with the retreating mother; and a neonate that scared away its mother when approaching her at full speed. Avoiding capture attempts of neonates $<10$ minutes old 
or those that achieve full coordination quickly, waiting for the mother to return to the neonate when she retreats as a result of markers moving toward the neonate, and refraining from capturing neonates when mothers cannot be clearly identified would reduce abandonment events.

Additional capture-induced abandonment (Livezey 1990) could result from confusion of visual and olfactory recognition. Occasionally, neonates followed workers upon release. Workers laying down immobile on the ground (even as close as $<1 \mathrm{~m}$ from the neonate) was an effective way to halt this behavior and caused neonates to switch attention to their mothers, the next closest moving object in sight. In a few cases, mothers became confused and followed retreating workers instead of their neonates. This behavior was most common in meadows, where tall grasses obstructed visual contact between mother and neonate. Lifting the neonate so that the mother could see it, or moving it to a more open area assisted the reunion process. Sometimes, mothers recoiled after sniffing the heads of the neonates, but this reaction passed and never appeared connected to any abandonments. In studies of other ungulates, failure to avoid transferring of human scents to neonates did not result in abandonment when capturing guanaco and white-tailed deer (Odocoileus virginianus) neonates (Franklin and Johnson 1994, Carstensen Powell et al. 2005). However, rubbing workers' hands and ear-tags with dirt and grass before capturing neonates, in order to reduce human-scent transfer, might be effective.

\section{MANAGEMENT IMPLICATIONS}

The method presented here, adapted from that described for guanacos, combined with the use of ear-tag transmitters, allows studying important biological aspects of juvenile vicuñas, including the estimation of perinatal mortality. This parameter is often overlooked in juvenile-ungulate survival analyses (Linnell et al. 1995, Gaillard et al. 2000). Although the hand-capture method has merit when studying juvenile ungulates, its benefits may be lowered if interspecific variability in biological and behavioral traits, even in closely related species, are ignored or unknown when designing capture strategies.

\section{ACKNOWLEDGMENTS}

Permits to conduct this research were issued by the Argentinean National Park Administration. We are thankful to A. Montañez, superintendent of SGNP, for providing logistical support. Park rangers J. Gallo, F. Marinero, J. Esquivel, I. Esquivel, J. Cavallero, D. Tapia, and 5 volunteers participated in vicuña captures. Funds for this project were granted to E.D. by Rufford Foundation, American Society of Mammalogists, Program in Ecology (UWYO, NSF EPS0447681), Cleveland Metroparks Zoo, National Geographic (CRE no. 8399-08), Department of Zoology and Physiology (UWYO), School of Renewable Resources (UWYO), Science Posse Program (UWYO), CREO, and Wildlife Conservation Society and; to A.J.N. by the Argentine Science Agency (ANPCyT, IM-40 grant).

\section{LITERATURE CITED}

Baigún, R. J., M. L. Bolkovic, M. B. Aued, M. C. Li Puma, and R. P. Scandalo. 2008. Manejo de fauna silvestre en la Argentina: primer censo nacional de camélidos silvestres al norte el Río Colorado. Dirección de Fauna Silvestre, Secretaría de Ambiente y Desarrollo Sustentable de, la Nación, Buenos Aires, Argentina. [In Spanish.]

Carstensen Powell, M., G. D. DelGiudice, and B. A. Sampson. 2005. Low risk of marking-induced abandonment in free-ranging white-tailed deer neonates. Wildlife Society Bulletin 33:643-655.

Franklin, W. L., and W. E. Johnson. 1994. Hand capture of neonate openhabitat ungulates-the South-American guanaco. Wildlife Society Bulletin 22:253-259.

Gaillard, J. M., M. Festa-Bianchet, and N. G. Yoccoz. 1998. Population dynamics of large herbivores variable recruitment with constant adult survival. TREE 13:58-63.

Gaillard, J. M., M. Festa-Bianchet, N. G. Yoccoz, A. Loison, and C. Toigo. 2000. Temporal variation in fitness components and population dynamics of large herbivores. Annual Review of Ecology and Systematics 31:367393.

Hofmann, R. K., K. C. Otte, C. F. Ponce del Prado, and M. A. Rios. 1983. El manejo de la vicuña silvestre. GTZ, Eschborn, Germany. [In Spanish.]

Lichtenstein, G. 2006. Manejo de vicuñas en cautiverio: el modelo de criaderos del CEA INTA Abrapampa (Argentina). Pages 133-146 in B. L. Vilá, editor. Investigación, conservación y manejo de vicuñas. Proyecto MACS, Buenos Aires, Argentina. [In Spanish.]

Lichtenstein, G., and B. L. Vilá. 2003. Vicuña use by Andean communities: an overview. Mountain Research and Development 23:197-201.

Linnell, J. D. C., R. Aanes, and R. Andersen. 1995. Who killed Bambi? The role of predation in the neonatal mortality of temperate ungulates. Wildlife Biology 1:209-223.

Livezey, K. B. 1990. Toward the reduction of marking-induced abandonment of neonate ungulates. Wildlife Society Bulletin 18:193-203.

Perrig, P. L., E. Donadio, J. A. Pereira, and D. Gómez. 2010. Uso de vegas por camélidos silvestres y pumas Puma concolor en la cordillera de San Juan, Argentina. Page 96. Proceedings of the XXIII Argentinean Meeting of Mammalogy. Argentinean Society of Mammalogists, 9-12 November 2010, Bahía Blanca, Buenos Aires, Argentina. [In Spanish.]

Puig, S., and F. Videla. 2007. Distribución, densidades y estado de conservación de los camélidos. Pages 197-223 in E. Martínez Carretero, editor. Diversidad biológica y cultural de los altos Andes centrales de Argentina-línea de base de la Reserva de Biosfera San Guillermo, San Juan. Editorial Fundación Universidad Nacional de San Juan, San Juan, Argentina. [In Spanish.]

Salvioli, G. 2007. Caracterización hidrometeorológica. Pages 63-87 in E. Martínez Carretero, editor. Diversidad biológica y cultural de los altos Andes centrales de Argentina-Línea de base de la Reserva de Biosfera San Guillermo, San Juan. Editorial Fundación Universidad Nacional de San Juan, San Juan, Argentina. [In Spanish.]

Sarno, R. J. 2010. Vicuña conservation: where do we go from here? GECS News 3:3-8.

Torres, H. 1992. Camélidos silvestres sudamericanos. Un plan de acción para su Conservación. International Union for Conservation of Nature/Species Survival Commission, Gland, Switzerland. [In Spanish.]

Vilá, B. L. 2002. La silvestría de las vicuñas, una característica esencial para su conservación y manejo. Ecología Austral 12:79-82. [In Spanish.]

Vilá, B. L., and G. Lichtenstein. 2006. Manejo de vicuñas en la Argentina. Experiencias en las provincias de Salta y Jujuy. Pages 121-135 in M. L. Bolkovic and D. Ramadori, editors. Manejo de Fauna Silvestre en la Argentina. Programas de uso sustentable. Dirección de Fauna Silvestre, Secretaría de Ambiente y Desarrollo Sustentable, Buenos Aires, Argentina. [In Spanish.]

Wheeler, J. C., and J. Laker. 2009. The vicuña in the Andean Altiplano. Pages 21-33 in I. J. Gordon, editor. The vicuña: the theory and practice of community-based wildlife management. Springer, New York, New York, USA.

White, M., F. F. Knowlton, and W. C. Glazener. 1972. Effects of damneonate fawn behavior on capture and mortality. Journal of Wildlife Management 36:897-906. 